\title{
Deepwater Horizon Oil Spill: An Ethics Case Study in Environmental Engi- neering
}

\section{Dr. Jonathan Beever, University of Central Florida}

Jonathan Beever is Assistant Professor of Philosophy and faculty with the Texts \& Technology Program at The University of Central Florida. He has held postdoctoral positions with Penn State's Rock Ethics Institute and with Purdue University's Weldon School of Biomedical Engineering before joining UCF. He has held fellowships with the Kaufmann Foundation, the Aldo Leopold Foundation, and the Global Sustainable Soundscape Network and has had research funded by the National Science Foundation. Jonathan's research focuses on questions of ethics, science, and representation. He teaches a wide variety of undergraduate and graduate courses on related topics.

\section{Dr. Justin L Hess, IUPUI, Indianapolis}

Justin L. Hess received his PhD from Purdue University's School of Engineering Education along with his Master's of Science and Bachelor of Science from Purdue's School of Civil Engineering. Justin is currently a Postdoctoral Researcher in the STEM Education Research Institute at IUPUI. Justin's research interests include developing pedagogical strategies to improve STEM students' ethical reasoning skills; exploring the role of empathy within design, innovation and sustainability; synthesizing the influence of societal and individual worldviews on decision-making; assessing STEM students' learning in the spaces of design, ethics, and sustainability; and exploring the impact of pre-engineering curriculum on students' abilities and career trajectories. 


\title{
Deepwater Horizon Oil Spill: An Ethics Case Study in Environmental Engineering
}

\begin{abstract}
The April 20, 2010 Deepwater Horizon oil rig explosion was an engineering and environmental tragedy that led to the loss of 11 human lives and has had far-reaching environmental and economic impacts, the full extent of which is difficult if not impossible to calculate. In 2015 the explosion continues to impact those 11 individual's families; it continues to have a far-reaching emotional impact on the 115 men and women on board at the time of the catastrophe; scientists are still evaluating the environmental impacts of both the oil dispersion throughout the gulf and the oil dispersant used to curtail the spill at surface depths. Simultaneously, gulf business owners, particularly those who rely on gulf waters for their livelihoods, continue to struggle. This novel and far-reaching real-world disaster is particularly salient for use within engineering curricula due to its inherently complex interplay of ethical issues and the broad scope of stakeholders impacted by the initial disaster and its aftermath.

We have developed and refined this real-world case study with students participating in a graduate level course at Purdue University over three separate years and five course offerings. We designed this case study within a unique pedagogical framework that leads students to reflectively adopt varying stakeholders' perspectives in order to reason through the case within a team setting. As a final goal, students must decide the appropriateness of continuing deepwater drilling throughout the Gulf of Mexico in light of the human, economic, environmental, and social implications of future potential blowouts. As part of the broader ethics course in which this case is embedded, we selected this case as it provides a uniquely broader scope of stakeholders and a more specific focus on the principles of nonmaleficence and justice when compared to the other cases presented to students. Whereas many engineering ethics case studies focus on human stakeholders and corporations, here the focus also includes marine and aquatic life, challenging a narrowly anthropocentric focus by placing environmental issues as a focal point. In this sense, our focus pushes beyond other case studies in ethics by addressing both macro-ethical issues, where students are encouraged to adopt a broadened societal viewpoint to deduce the most ethical courses of action, and micro-ethical issues, where the focus is towards the professional obligations of an individual engineer, through a scaffolded staged pedagogy.
\end{abstract}

In this paper we present the case structure and pedagogy to argue for the relevance of this unique, novel, and effective case for increasing engineering students' ethical reasoning abilities, particularly broadening their awareness of the scope of stakeholders impacted by engineering decisions and their ability to empathize with those stakeholders.

Keywords: Engineering ethics; Ethical reasoning; Case study; Deepwater Horizon; Reflexive Principlism 


\section{Introduction}

The April 20, 2010 Deepwater Horizon oil rig explosion in the Gulf of Mexico was a tragedy that led to the loss of 11 human lives. In 2015 the explosion continues to impact those 11 individual's families; ${ }^{1}$ it continues to have a far-reaching emotional impact on the 115 men and women on board at the time of the catastrophe; ${ }^{2}$ scientists are still evaluating the environmental impacts of both the oil dispersion throughout the gulf and the oil dispersant used to curtail the spill at surface depths. ${ }^{3}$ Simultaneously, gulf business owners, particularly those who rely on gulf waters for their livelihoods, continue to struggle. Nonetheless, deep-water drilling continues to expand throughout the gulf into ever deeper terrain ${ }^{4,5}$ and, for the first time ever, the U.S. federal government approved deep-water drilling within arctic waters in August 2015. ${ }^{6}$ The pace of technological development is allowing oil drillers to venture into more and more remote terrain and, as a result, to take more and more substantial risks. Despite the gulf tragedy, there is no hint of slowing the exponential advancement of deep-water drilling throughout U.S. waters soon.

We have developed and refined this real-world case study with students participating in a graduate level engineering ethics course at Purdue University over three separate years and five course offerings. We selected this case as it provides a uniquely broader scope of stakeholders and a more specific focus on the principles of non-maleficence and justice when compared to the other cases presented throughout the course. Specifically, this case challenges students to consider the appropriateness of increasing the risk of engineering technologies in light of the distribution and impact that their potential failure will have on a broad range of stakeholders. Additionally, whereas many engineering ethics case studies focus on human stakeholders and corporations, here the focus also includes marine and aquatic life, challenging a narrowly anthropocentric focus by placing environmental issues as a focal point. In this sense our focus pushes beyond both macro-ethical issues, where students are encouraged to adopt a broadened societal viewpoint to deduce the most ethical courses of action, and micro-ethics, where the focus is towards the professional obligations of an individual engineer. ${ }^{7,8}$

The case as we designed it challenges students to justify the ethicality of deeper water drilling in light of this disaster, guided by the reflective specification and balancing of four core and universal ethical principles: beneficence, non-maleficence, justice, and respect for autonomy, ${ }^{9}$ through an ethical reasoning process that Beever and Brightman described as reflexive principlism. ${ }^{10}$ Our focus is on the range of stakeholders impacted, the allocation of risk when novel technologies emerge, and the specification and balancing of core ethical principles in light of numerous, diverse, and sometimes conflicting stakeholder perspectives. As a final goal for this case study, students collaborate on a group case report to reason through the ethicality of deeper and riskier oil drilling within the Gulf of Mexico. In writing their group case report, students may justify their responses by referring to issues not directly covered; such issues might include the nature of oil production and use, energy production and distribution throughout the United States and worldwide, the politics of oil, or wars fought over oil. Indeed, each of these issues is worthy of an entire semester's content in their own right. In a two or three-week period, we explicitly focus on the immediate events leading up to and the aftermath of the spill. 


\section{Our Objective}

In this paper, our objective is to describe how this case study may be presented within engineering curricula to enhance students' ethical reasoning development, particularly their ability to empathize with diverse stakeholders involved in a case and to depict a just course of action in light of the complex risk distribution of emergent technologies.

\section{Ethical Analysis through Case-Based Pedagogy}

Case studies are one of the most prominent means of engaging engineering students in ethics. Highly visible cases, particularly disaster cases, are commonly used. ${ }^{11,12}$ Although coursespecific learning objectives should drive the pedagogical strategy employed by engineering ethics educators ${ }^{13}$ and the disciplinary realm should play a key role in deciding the relevance of a case $^{14}$, in general, Harris Jr. and colleagues considered the usage of case studies as the "best way to teach engineering ethics" as students learn to "draw the line" between "acceptable and unacceptable actions." $" 15$

When designed well and integrated appropriately, case studies can enable students in postsecondary curricula to reach higher stages of moral development. ${ }^{14,16}$ Furthermore, effective case studies can promote students to transfer knowledge outside of the course to real-world situations, especially cases with which students become emotionally engaged. ${ }^{17}$

We posit that empathic perspective-taking with all key stakeholders is necessary for effectively justifying a response to any case. ${ }^{18}$ Instructors have regularly argued for user-centric or empathic understanding through performative role-playing activities, where students-as-actors imaginatively situate themselves within one or more stakeholders' positions to embody and articulate differences in value claims. Generally, instructors elicit these role-playing activities within a facilitated discussion environment; as a result, this collectively increases the number of perspectives each individual student considers. Role-playing exercises have been used successfully throughout a variety of engineering ethics endeavors, including but not limited to case studies. ${ }^{19-21}$ As described by Doorn and Kroesen ${ }^{19}$, role-playing exercises are particularly useful as they "broaden students' perspectives." Further, role-playing discussions allow students to drive the discourse; the leading professorate becomes a facilitator rather than a "preacher." 22

As part of the staged pedagogical framework we used to develop this case, we have integrated "perspective-taking" activities which are similar to those role-playing activities in that they seek to develop empathic understanding of others' value claims and case-specific perspectives. We elaborate on this framework next, and in the subsequent sections we describe how we have situated the Deepwater Horizon case study within this framework.

\section{SIRA Pedagogical Framework}

The structure of the case study, as we have designed it in alignment with the SIRA pedagogy, ${ }^{23}$ includes higher levels of supportive materials in the earlier stages to assist students in gaining knowledge regarding the scope of the case and confidence in responding to the case. The direct role of the instructor shifts from provider of expert information to facilitating coach of ethical reasoning as the case study proceeds. Our focus throughout the case is on two core issues of (a) 
allocation of risk and (b) stakeholder impact. This is exemplified through the videos we have developed, selected readings, discussion prompts, quick checks, and the group case report prompt. Naturally, many case-specific facts and issues that we do not explicitly prompt arise through in-class discussion, the group case reports, and the asynchronous on-line posting which is driven by student interest.

One of the strengths of the pedagogical strategy we utilized is that students must work together to justify their responses based off each student's knowledge and interests, collectively gathered and synthesized. A diversity of viewpoints is essential for pushing the discourse in novel directions and for an authentic, active-learning pedagogy. The six-staged pedagogical framework we used to design this case included scaffolding the content, incorporating interactive activities, and ending the case with reflective analysis (hence, the SIRA acronym). ${ }^{23}$ Each of these stages is key for engaging students in the course content and for the holistic development of their ethical reasoning abilities. Scaffolded and staged content, key to this pedagogical framework, enables student interaction with and reflection on case content.

\section{Stage by Stage Overview}

\section{Stage 1: Establishing Knowledge}

In order to provide students with sufficient material to allow them to feel confident in responding to the case, our initial focus is on providing technical details surrounding the case. Specifically, we present students with content describing the scenario, facts, scope of impact, and other general information. As the ultimate focus of the case is for students to justify the ethicality of continuing deep-water drilling in the Gulf of Mexico, we prime students to keep the following prompt in mind as they work through the case content: "There are overlapping technical and ethical questions to consider here: How can we prevent future disasters like the Deepwater Horizon disaster? Should we be engineering ways to drill in the Gulf of Mexico?" Following this preliminary text, the case opens with a narrative video that proceeds as follows:

At nearly 20 times larger than the 1989 Exxon Valdez oil spill, the 2010 Deepwater Horizon oil spill leaked nearly 210 million gallons of crude oil into Gulf of Mexico. As a case study in engineering ethics, this one's particularly fascinating for its scope of stakeholders and the complexity of ethical values involved. From economic welfare to human health, to environmental welfare, to non-human health, the complexity of values and conflicts in values make this a great case for thinking through the specification of principles. Compounding conflicts of ethical values in an already complex case, epistemic issues add another layer of complexity to the issue. Just as an example, reports of the spill rate changed dramatically in the first days of the disaster. In what follows, we're going to apply reflexive principlism to this highly complex case-one that continues to unfold in terms of conflict and consequence. It's a great example of the relationship between ethics and engineering.

After watching this short introductory video, students work through a series of readings, videos, and associated "quick checks"; the intent of these quick checks is to ensure students have a grasp of basic information pertaining to the case. 
The first stage has three distinct parts: (a) an overview of the technical details of the rig setup, spill, and its containment, (b) the varying estimates of the oil spill rate immediately following the explosion, and (c) an overview of the current state of deep-water drilling in the Gulf of Mexico. For example, we first provide students with a cross-section visualization of the rig operations with respect to the wellhead and the oil reservoir.

To expose students to the oil spill volume estimation process, we use videos from Dr. Steve Wereley's CNN interview with Anderson Cooper and his testimony with the U.S. House of Representatives. At the time of this interview, Dr. Wereley was a mechanical engineering professor at Purdue University; he used Particle Image Velocimetry to approximate the oil flow rate out of one of the riser pipes. At the time of his testimony, BP was using an oil spill estimate of 5,000 barrels per day. Dr. Wereley testifies, "I don't see any possibility, any scenario under which their number is accurate [...] it is fully an order of magnitude higher than what BP projects, without question." While Wereley's final estimates were in the range of 56,000 to 84,000 barrels per day, the "official" estimate of the overall spill started at 62,000 barrels per day and, as the spill continued, decreased to 53,000 barrels per day. By adding in the 800,000 barrels captured (from the official estimate, that is), the final estimate was 4.9 million barrels of oil spilled. This total was within the range of some scientific estimates ${ }^{24}$ but was well below Dr. Wereley's approximations. This epistemic discrepancy introduces students to the importance of expertise and the role and nature of technical information in ethical decision-making.

For the third component, we send students to two websites. The first provides an overview of the current number of drills operating in the Gulf. Due to the volatility of crude oil prices (thanks, in part, to domestic crude production from hydraulic fracturing), the number of rigs in operation has varied widely since the 2010 spill, but still averages around 50 rigs in operation per year since the explosion. ${ }^{25}$ As of June 2015, there was an industry wide push for growth. ${ }^{26}$

Here, our focus is on the site-specific impact, although we recognize that there are broader ethical issues surrounding the case. For example, we do not require students to explore global oil industry politics and distribution ${ }^{27}$ nor to investigate oil ownership ${ }^{28}$. Furthermore, this case has a robust history with criminal suits continuing long after the fact, the development or change of EPA regulations, local stakeholders' efforts to regroup from the spill, and oil production continuing and rapidly growing throughout the Gulf, Alaska, and other regions of the world. While these novel additions are important, our primary focus in Stage 1 is on helping students gain enough technical factual knowledge of the case to then engage with issues of risk and potential harms inherent to deep-water drilling and other emerging technologies, along with the inter-connectedness of stakeholders impacted by disasters such as this one.

Immediately following these activities, and upon completion of all associated "quick checks", the case module transitions to Stage 2 where the focus is on stakeholder impact.

\section{Stage 2: Perspective Taking}

In this second stage, our initial goal is to develop students' awareness of the broad scope of stakeholders impacted by the Gulf oil spill. These stakeholders include but are not limited to BP and its workers (including employees who were operating the rig or drilling, as well as executives and off-site employees), Transocean Ltd. (the owner and operator of the rig) and its 
workers, Haliburton and its workers (who performed the cement work around the casing of the well), Schlumberger and its workers (who were responsible for testing the efficacy of the cement strength but evacuated the rig the day of the explosion), the families of those employees who were killed or injured by the explosion, the marine life impacted by the 87 days of steady oil and gas flow into the ocean, the business owners who rely on fisheries, tourism, and associated activities across the Gulf States, the U.S. Government (including the Coast Guard, the Minerals Management Service, and the commission created to examine facts concerning the Deepwater Horizon, known as the National Commission on the BP Deepwater Horizon Oil Spill and Offshore Drilling or the "Chief Counsel"), scientists involved in predicting the oil flow rates and environmental impact, consumers of oil (particularly those in the United States), and other deepwater drilling organizations (e.g., Shell, Exxon) and their employees.

In Stage 2, there are two distinct categories of readings we assign to students, where we have them differentiate between human and non-human stakeholders. The initial reading is on the 11 lives lost during the explosion, which shifts directly to the financial charges against BP, and ends with an article on the economic impact of the spill to business owners who rely on the Gulf waters for their livelihoods. Next, the focus shifts to the Gulf Wildlife report and the "dirty blizzard".

Stage 2 ends with a perspective-taking prompt that students post on-line asynchronously and then respond to their peers' posts. The purpose of this activity is to have students begin developing their own stance on ethical issues and questions of stakeholder relevance presented throughout the case prior to coming to class for a facilitated dialogue. Further, as most of the students in the course will not pursue careers that entail working on an oil rig, we seek to help students make associations between this case and their own experiences or disciplinary issues. These prompts include:

1. How do we weigh the various stakeholder claims in this case?

2. In what ways do some engineers (e.g., those working on a rig in the Gulf of Mexico) have a different scope of ethical concerns than other engineers?

\section{Stage 3: Comparing and Contrasting Perspectives}

As in-class students participate in class during the third stage, we begin the discussion by revisiting details presented in Stages 1 and 2. Once students respond to a series of questions regarding the case, we quickly transition to more complex ethical issues. Through this dialogue, we reinforce content students should already have a grasp on and we seek to overcome any of their misconceptions or uncertainties regarding the case facts or details.

As the discussion progresses, we seek to direct the conversation so that students, at a minimum, specify four key normative principles and consider how to balance these principles with respect to the broad scope of stakeholders impacted. The more student-driven the dialogue, the better. In this manner students can translate the case issues to ethical issues that they have encountered (within the case or beyond) or that they have found most intriguing. One of the key issues students commonly debate is, "What does it mean, and how do we 'respect the autonomy' of non-rational animals when we decide about future drilling, such as the crustaceans and marine mammals impacted by the spill?" 


\section{Stage 4: Inducing Conflict}

Stage 4 challenges students' stances through additional ethically-relevant concerns that we group into three sections: (a) risks associated with deep-water drilling, (b) the "greening" of oil companies, and (c) the rigs to reefs program. As the first part illustrates, deep-water drilling is an inherently risky business, and blowouts are by no means uncommon, unprecedented, or unexpected. For example, Noynaert and Schubert suggested that "blowouts will always happen no matter how far technology and training advance. ${ }^{29}$ Nonetheless, oil producers (including but not limited to BP) have bolstered their public image regarding their commitment to sustainability through green communication. ${ }^{30,31}$ As a review of BP's history shows, at least in regards to decisions made from the top BP executives, this has been mostly bark with no bite. ${ }^{32}$ Lastly, we shift the focus to positive environmental impacts of deep-water drilling; the decommissioning of rigs in Gulf shores to form artificial reefs. ${ }^{33}$

The discussion prompt in this stage initially focuses on the ethicality of deep-water drilling. It transitions to a focus on students' moral intuitions in relation to their ethical reasoning approach to the case. With this transition, the case becomes a backdrop for students to reflect on their overall process of ethical reasoning, as the discussion prompt moves from case-specific to process-specific. The prompt asks:

1. How do the benefits of deep-water drilling compare to the risks, even if we grossly overengineer fail-safes?

2. Think on your ethical intuitions - your feelings about right and wrong - in this case. Do they tell you that the benefits of building and operating the Deepwater Horizon were worth the risk and consequences?

3. As an engineer, what constraints could get in the way of following your ethical intuitions in this case?

4. What role do your moral intuitions play in the process of ethical decision-making within reflexive principlism?

\section{Stage 5: Decision-making and Justification}

Stage 5 begins with another facilitated discussion. Here the focus shifts from intuitions and emotional responses to reasoned responses. Students are asked to give reasons for a particular stance, guided by their work in previous stages, regarding the ethicality of continuing deep-water drilling throughout the gulf. The in-class discussion is an extension of all previous materials, but the primary focus pertains to risk assessment. We press students to consider, "Is there a certain level of risk that is too much ethically?" and "What is the relationship between innovation and risk?" In this discussion, we also consider why oil companies engage in green-washing and we try to focus on the potential benefits of oil drilling. Following this discussion, students are assigned a case report that they work through in teams of four to five students in roughly a week.

\section{Stage 6: Reflection and Reflexivity}

Lastly, students reflect on the case material, particularly the relationship between the ethical principles and the case content. Here, we provide students with the following prompt: 
Reflexive principlism requires both specification and prioritization of ethical principles. In light of the case details and the applicable ethical codes, how do you specify and prioritize the principles in this case? (Students rank autonomy, beneficence, nonmaleficence, and justice on a 5-point scale where 1 = top priority, $2=$ second priority, 3 $=$ third priority, $4=$ fourth priority, and $5=$ no priority). Explain your answer. For any conflict between principles, state how you resolved the conflict.

Conscious reflection on a student's own ethical decision-making process, we believe, further engages students in class, and we hope motivates them to act as ethical agents beyond the class and in their future professional careers. Reflection draws learners into a deliberative reiteration of the six-stage ethical decision-making process, with revisions or reinterpretations leading to comparatively refined conclusions.

\section{Summary}

The Deepwater Horizon oil spill is a novel, unique, and effective engineering ethics case study for promoting students' ethical reasoning development. In this paper, we have argued that this case is particularly useful for developing students' tendency to consider the broad scope of stakeholders impacted by engineering decisions, including human and non-human stakeholders. It also challenges students to think through the distribution of risks when innovative and emergent technologies are produced. Further, our experiences in delivering the engineering ethics course have indicated that this case, as designed and facilitated, successfully generated students' emotional engagement. In the future, we will further analyze students' responses to the case activities in order to explore the impact of this case study, situated in its pedagogical framework, on students' ethical reasoning development and perspective taking tendencies.

As a final note, at the time of this writing, the oil spill, its impact, and BP ramifications are still present in the news. In light of this ongoing case, the content described should be considered dynamic rather than static. Nonetheless, to the extent possible, the structured framework and ethical reasoning approach should be held constant in future revisions or course offerings of this case for those seeking to maximize the impact of this case on students' ethical reasoning development.

\section{Acknowledgements}

This work was made possible by an Engineer of 2020 Seed Grant from the College of Engineering and by the National Science Foundation (Grant No. 1237868) as part of the Ethics Education in Science and Engineering program. Any opinions, findings, and conclusions or recommendations expressed in this material are those of the authors and do not necessarily reflect the views of the National Science Foundation. We wish to thank the intellectual encouragement of the "PRIME Ethics" team and especially Andrew Brightman for his input and ongoing support of this work. 


\section{References}

1. Drash, W. (2015). Imagining daddy: A rig worker's daughter and her dreams. Retrieved September 2, 2015, from http://www.cnn.com/2015/04/10/us/oil-rig-victim-families-five-years-later/

2. Juhasz, A. (2011). Black tide: The devastating impact of the gulf oil spill. Hobokon, NJ: John Wiley \& Sons.

3. Li, F. J., Duggal, R. N., Oliva, O. M., Karki, S., Surolia, R., Wang, Z., . . Antony, V. B. (2015). Heme Oxygenase-1 protects Corexit 9500A-induced respiratory epithelial injury across species. PloS one, 10(4).

4. Klimasinska, K. (2012). Deepwater permits in U.S. Gulf exceed pre-BP spill level. http://www.bloomberg.com/news/print/2012-10-17/deepwater-permits-in-u-s-gulf-exceed-pre-bp-spilllevel.html

5. Burdeau, C. (2015). 5 years after BP spill, drillers push into riskier depths. Retrieved August 18, 2015, from http://bigstory.ap.org/article/260b1dbc50c548ba8af576bc75014a03/5-years-after-bp-spill-drillers-push-riskierdepths

6. BSEE. (2015). BSEE approves updated permit for exploration activities in arctic waters under rigorous safety requirements. Retrieved August 18, 2015, from http://www.bsee.gov/BSEE-Newsroom/PressReleases/2015/BSEE-Approves-Updated-Permit-for-Exploration-Activities-in-Arctic-Waters-Under-RigorousSafety-Requirements/

7. Newberry, B. (2010). Katrina: Macro-ethical issues for engineers. Science and Engineering Ethics, 16(3), 535571.

8. Herkert, J. R. (2003). Professional societies, microethics, and macroethics: Product liability as an ethical issue in engineering design. International Journal of Engineering Education, 19(1), 163-167.

9. Beauchamp, T. L. (2007). The 'four principles' approach to health care ethics. In R. Ashcroft, A. Dawson, H. Draper \& J. McMillan (Eds.), Principles of health care ethics (2nd ed., pp. 3-10). West Sussex, UK: Wiley.

10. Beever, J., \& Brightman, A. O. (2015). Reflexive principlism as an effective approach for developing ethical reasoning in engineering. Science and Engineering Ethics.

11. Haws, D. R. (2001). Ethics instruction in engineering education: A (mini) meta-analysis. Journal of Engineering Education, 90(2), 223-229.

12. Harris Jr, C. E., Pritchard, M. S., Rabins, M. J., James, R., \& Englehardt, E. (2014). Engineering ethics: Concepts and cases, 5th ed. Boston, MA: Cengage Learning.

13. Li, J., \& Fu, S. L. (2012). A systematic approach to engineering ethics education. Science and Engineering Ethics, 18(2), 339-349.

14. Huff, C., \& Frey, W. (2005). Moral pedagogy and practical ethics. Science and Engineering Ethics, 11(3), 389408.

15. Harris Jr, C. E., Davis, M., Pritchard, M. S., \& Rabins, M. J. (1996). Engineering ethics: what? why? how? and when? Journal of Engineering Education, 85, 93-96.

16. Rest, J. R., \& Narvaez, D. (1994). Moral development in the professions: Psychology and applied ethics. Hillsdale, NJ: Lawrence Erlbaum Associates.

17. Thiel, C. E., Connelly, S., Harkrider, L., Devenport, L. D., Bagdasarov, Z., Johnson, J. F., \& Mumford, M. D. (2013). Case-based knowledge and ethics education: Improving learning and transfer through emotionally rich cases. Science and Engineering Ethics, 19(1), 265-286.

18. Gibbs, J. C. (2013). Moral development and reality: Beyond the theories of Kohlberg, Hoffman, and Haidt (3rd ed.). New York, NY: Oxford University Press.

19. Doorn, N., \& Kroesen, J. O. (2013). Using and developing role plays in teaching aimed at preparing for social responsibility. Science and Engineering Ethics, 19(4), 1513-1527.

20. Brummel, B. J., Gunsalus, C. K., Anderson, K. L., \& Loui, M. C. (2010). Development of role-play scenarios for teaching Responsible Conduct of Research. Science \& Engineering Ethics, 16(3), 573-589.

21. Loui, M. C. (2005). Ethics and the development of professional identities of engineering students. Journal of Engineering Education, 94(4), 383-390.

22. Raisner, J. (1997). Using the "ethical environment" paradigm to teach business ethics: The case of the Maquiladoras. Journal of Business Ethics, 16(12-13), 1331-1346.

23. Kisselburgh, L., Zoltowski, C. B., Beever, J., Hess, J. L., Iliadis, A., \& Brightman, A. O. (2014). Effectively engaging engineers in ethical reasoning about emerging technologies: A cyber-enabled framework of scaffolded, integrated, and reflexive analysis of cases. Paper presented at the 121st ASEE Annual Conference \& Exposition, Indianapolis, IN. 
24. McNutt, M. K., Camilli, R., Crone, T. J., Guthrie, G. D., Hsieh, P. A., Ryerson, T. B., . . Shafferd, F. (2012). Review of flow rate estimates of the Deepwater Horizon oil spill. Paper presented at the Proceedings of the National Academy of Sciences of the United States of America.

25. Chamberlin, A. (2015). Gulf of Mexico rig count begins to lose strength. Retrieved September 21, 2015, from http://marketrealist.com/2015/04/gulf-mexico-rig-count-begins-lose-strength/

26. Taylor, M. (2015). Lawmakers push to expand offshore drilling in the Gulf of Mexico. Retrieved September 21, 2015, from https://www.wsws.org/en/articles/2015/06/04/gulf-j04.html

27. Inkpen, A., \& Moffett, M. H. (2011). The global oil \& gas industry: Management, strategy, \& finance: PennWell Corporation.

28. Klare, M. T. (2001). Resource wars: The new landscape of global conflict. Henry Holt and Company, LLC.

29. Noynaert, S. F., \& Schubert, J. J. (2005). Modeling ultra-deepwater blowouts and dynamic kills and the resulting blowout control best practices recommendations. SPE/IADC.

30. Domenec, F. (2012). The "greening" of the annual letters published by Exxon, Chevron, and BP between 2003 and 2009. Journal of Communication Management, 16(3).

31. Hendry, J. R., \& Vesilind, P. A. (2005). Ethical motivations for green business and engineering. Clean Technology and Enviornmental Policy, 7, 252-258.

32. Lusgarten, A. (2012). Run to failure: BP and the making of the Deepwater Horizon disaster. New York: W. W. Norton \& Company.

33. Kaiser, M. J. (2006). The Louisiana artificial reef program. Marine Policy, 30(6), 605-623. 